\title{
Australia and APEC in 2007
}

John Howard M.P.

Discurso pronunciado por el Primer Ministro de Australia en la Asia

Society Australasia Centre (Sydney, 6 de junio de 2007)

I want to congratulate the Asia Society AustralAsia Centre on a decade of helping to build understanding in Australia of Asian countries -their politics, business and culture.

I particularly want to recognise the contribution Hugh Morgan has made as the Society's Chairman, knowing that he will be stepping back from this role at the end of this month.

My focus tonight is on Australia's large and ambitious agenda this year for APEC. APEC is a vital piece of regional architecture for a rising Australia in a region that will be the cockpit of history in the $21^{\text {st }}$ Century.

The Asia Pacific region is coming of age. Its voice will be increasingly influential in global councils. APEC economies account for more than half of global GDP and nearly half of world trade.

APEC is also important to our economy and to Australian jobs. Around 70 per cent of Australia's total trade is with these economies, with eight of our top 10 trading partners in APEC. APEC economies also account for roughly two-thirds of all international visitors to Australia.

Australia was very much present at the creation of APEC and both sides of politics have seen it as the region's most important grouping.

APEC began in 1989 under Bob Hawke's leadership, when Australia hosted the first annual meeting of foreign and trade ministers against the backdrop of the final throes 
of the Cold War. Paul Keating was instrumental in the first annual meeting of APEC leaders, held at Blake Island, near Seattle, in 1993.

It is fair to acknowledge that APEC has not always delivered as quickly or as dramatically as some of its critics would like. Those hankering for some Asian variant of the European Union -replete with pooling of sovereignty and a rulesbased, top-down approach- have been disappointed.

So have those who aspire to a more homogenised, structured community premised on some distinctive set of values.

The sheer diversity and dynamism of the region have thwarted any attempt to impose such order. Regional forums continue to proliferate-ASEAN and APEC have been joined not just by the ASEAN Plus Three but now by the East Asia Summit, of which Australia is a founding member.

Each of these groupings has a slightly different membership, rationale and agenda. Each plays a role in strengthening linkages and building up habits of cooperation in a region where many historical issues remain unresolved and where working together has not always been the norm.

The search for a single overarching construct for the region remains elusive. Based on my experience, this is entirely to be expected.

The Asia Pacific region is not Europe. The geography is different. The history is different. And the issues we face are often different.

What has APEC achieved, and what can it achieve in the future?

In my view, one of APEC's most important contributions is its distinctive regional style and approach to addressing problems.

Much of APEC's best work is done under the radar. It's not as dramatic or as eyecatching as formal treaties. But it makes a measurable difference to people who live and work in our region.

APEC's work on customs facilitation and on electronic commerce is a case in point, increasing transparency and commonality between regimes and reducing red tape. So 
too is the APEC Business Travel Card, which greatly simplifies the movement of eligible business people through the region's airports.

Regular meetings of APEC officials and ministers to discuss health, transport and other shared challenges are making a practical contribution to solving problems and helping to build useful regional networks. These serve to thicken up the web of bilateral and multilateral connections which underpin the stability and prosperity of the region.

APEC also has a strong record of responding to major issues that periodically confront the international community.

Discussions among leaders at the Auckland meeting in 1999 played an important part in galvanising and fashioning the international response to the independence crisis in East Timor.

Discussions in Shanghai in October 2001 were important in securing China's entry into the World Trade Organisation -one of the most significant (and underrated) global developments in our lifetimes. At the same meeting, just after the 9/11 terrorist attacks, APEC leaders also took a united stand in the face of this clear and present global threat.

In 2003, they responded firmly and practically at their Bangkok meeting to the regional SARS outbreak. And last year's meeting in Hanoi issued a strong condemnation of North Korea's nuclear test -a statement all the more important because it came from those countries with most to lose from a nuclear-armed North Korean regime.

I think we can go further than this, however. APEC needs to do more than react to big events as they arise. It needs to speak clearly, consistently and with confidence on the great global governance challenges of our age.

APEC works best when it sets a broad shared objective without seeking to be overly prescriptive about how member economies should pursue it. This recognises the legitimacy that resides in national governments and that many of the levers required to respond to globalisation and transnational problems remain in their hands. 
APEC's strength lies in its ability to build consensus that a problem exists and to develop practical concerted responses. This process is not always quick, and we are keen to reform APEC's structures to improve its responsiveness.

Australia has proposed strengthening the existing secretariat by establishing an APEC policy support unit and also by appointing an APEC executive director for a set term.

\section{REGIONAL ECONOMIC INTEGRATION AND GLOBAL TRADE}

APEC has remained committed to the principle that openness is the key to enhancing regional prosperity and stability by encouraging the flow of goods, services, capital and technology.

APEC economies have made considerable progress on the path towards regional economic integration. Tariffs across the APEC region have declined from an average of almost 17 per cent in 1989 to just over 5 per cent today.

In addition to facilitating regional economic integration, APEC has demonstrated the ability to throw its weight effectively behind global trade liberalisation efforts. It did this most notably in 1993 when APEC helped push the Uruguay Round of trade negotiations over the line to a successful conclusion.

This year's leaders meeting will again find the world trade system at a critical point. Protectionist sentiment is again on the rise, including in parts of the developed world.

The stakes are very high. The outlook for world economic growth is positive, but the collapse of the Doha Round would send a very negative signal to economic decisionmakers around the world.

Australia's economic interests would be seriously jeopardised. Our region -which is both a major driver and beneficiary of global economic growth-would also be harmed.

And developing nations -which stand to gain far more from open markets than they do from foreign aid or debt relief- would suffer more than anyone else.

Australia has put its full weight behind securing a good 
outcome to the Doha Round. I recently wrote to the leaders of the United States, the European Union, Brazil, India, Japan, Germany (as current president of the G8) and Indonesia (as chair of the G33 group of developing countries) to underline the importance of the Round and to urge them to take the necessary steps to take forward negotiations, particularly on agriculture.

I will take advantage of Australia's chairmanship of APEC to press leaders for a strong statement of support for the Round. With US elections in 2008, time for a good outcome is running out.

Should the Round fail, Australia will have to look to other options. We have negotiated free trade agreements with New Zealand, Singapore, Thailand and the United States. Other negotiations in the region - including with Japan, China, Malaysia and ASEAN - are underway.

The benefits of FTAs are maximised if they are comprehensive, not only in terms of sectors but also in their coverage of regional markets. Achieving a Free Trade Area of the Asia Pacific (FTAAP), as proposed by the United States, represents a significant challenge. But this proposal represents a live option -and one which would take on greater prominence should the Round fail.

Increasingly barriers to trade do not take the form of tariffs or quotas. APEC's facilitation agenda is in part a response to this. 'Behind the border' issues -including regulatory structures and competition policy-are also increasingly prominent.

Structural reforms to address impediments will help sustain economic growth in the region. This will also be an important theme in September.

APEC can provide a forum for exchanges of experiences on successful reform processes undertaken by other economies. Australia is well placed to lead further debate about structural reform having embraced almost a quarter century of extensive and continuous economic reform.

The fruits of these difficult, but necessary, decisions can be seen in today's National Accounts figures which show an extraordinary level of economic growth given the worst drought in 100 years. 
They underline again the threat to economic growth, jobs and living standards from any reversal of the key reforms of the past 25 years.

Australia also wants to build a stronger partnership with business in APEC through engagement with the APEC Business Advisory Committee (ABAC). The 2007 Business Summit promises to be a valuable opportunity for genuine dialogue between economic leaders and business delegates.

\section{Climate change}

In March I wrote to all APEC Leaders setting clean development and climate change as a focus of discussions in September.

The Sydney Summit will be one of the most important international gatherings of Leaders to discuss climate change since the 1992 Rio Conference. The Australian Government sees this as an historic opportunity to build consensus on a practical way forward for tackling climate change.

The world needs a new template to address this serious global challenge.

There is, I believe, increasing awareness that the Kyoto Protocol has serious shortcomings which prevent it being a credible blueprint for future action.

A simple statistic highlights these flaws. During the Kyoto time frame, China and India will build almost 800 new coal-fired power plants. The combined $\mathrm{CO} 2$ emissions from those plants will be five times the total reductions in $\mathrm{CO} 2$ mandated by the Kyoto accord.

Yet the future challenge is even starker. As the Emissions Trading Task Group observed, even if developed countries achieve a 50 per cent reduction in their total emissions by 2050, emissions will still remain above today's levels unless a significant cut in emissions growth was also achieved by the developing world.

We are not talking here about some minor technical failure with the Kyoto Protocol. We're talking about a 
gaping structural flaw, one that rests ultimately on an outmoded view of global power relations in the $21^{\text {st }}$ Century.

The respected foreign policy analyst, Fareed Zakaria, highlighted this recently when he wrote: «Kyoto represents old thinking: if the West comes together and settles on a solution, the Third World will have to adhere to that template. It's the way things have been done in international affairs for decades, perhaps centuries».

The only problem is it won't work in the $21^{\text {st }}$ Century. It won't work because economic and political power is shifting increasingly to the developing world and, geographically, from the Atlantic to the Pacific.

I've spoken about this often through the prism of a new global middle class with its epicentre in Asia. The new template for climate change must reflect this changing power equation.

The Kyoto model -top-down, prescriptive, legalistic and Euro-centric- simply won't fly in a rising Asia Pacific region.

It relies on trying to force countries to take on unrealistic obligations and then punishes them for failing. The world's developing countries have made clear that they will not accept short-term, Kyoto-style emissions limits.

Any meaningful regional discussion on climate change must recognise legitimate national aspirations for economic growth and energy security. No country -least of all rising economic superpowers like China and India- is going to embrace measures that imperil these objectives.

The post-Kyoto template needs to be more bottom-up, cooperative and flexible. It needs to take greater account of specific national circumstances and aspirations. And it's against this backdrop that I believe APEC can add real value.

APEC accounts for 60 per cent of the world's energy demand, and across the group demand is expected to double by 2030 .

It includes the world's largest two emitters -the United States and China (which together will soon generate half of global emissions)- as well as Indonesia (which according to some estimates is the third largest global emitter). It 
also includes key partners of Australia in the UN Climate Convention Umbrella Group (Japan, Canada, New Zealand and Russia).

Australia would like APEC Leaders to help design a new approach for future climate change action that could include all major emitters. We believe the principles on which this should rest include:

-respect for differences in national circumstances, including energy sources, resource endowments and development imperatives; -reliance on practical and cooperative action on emissions reduction, including through technology partnerships and forest stewardship; and -development of a more bottom-up approach to national commitments towards a shared goal, similar to APEC's philosophy of 'concerted unilateralism'.

These principles apply to an international domain the concept of 'well-governed' flexibility that I have extolled in a domestic context.

To help build consensus in the region, I announce tonight that I am appointing the Secretary of the Department of Foreign Affairs and Trade, Michael L'Estrange, as my special envoy to promote this initiative. Given the important role of business in APEC, I have also asked Mark Johnson from ABAC to help build support for Australia's objectives in the regional business community.

I believe APEC can support an emerging, practical consensus on a global framework for tackling climate change that is more comprehensive, more multi-faceted and more flexible than the Kyoto-style approach.

One model would be a so-called 'pledge and review' framework which allows countries flexibility to frame objectives and actions in a wide range of different forms. Some of these could be quantitative (such as emissions targets or carbon taxes). Others could be performance-based, for example, by linking the take-up of specific technology to a given date or to energy efficiency, research and development and adaptation objectives.

Pledges would typically be reviewed after a period of time, with a view to promoting additional action.

In the period since I wrote to APEC Leaders in March, 
I have been encouraged by the new ideas coming out of this region for concerted global action.

Before his major speech a couple of weeks ago, I spoke to Prime Minister Shinzo Abe of Japan and we agreed that the Asia-Pacific region should take the lead in defining future global climate change architecture. I welcome his thinking on the need for a post-Kyoto framework which includes all major emitters and takes account of national flexibility.

Some weeks ago I spoke to President Bush to enlist his support for an ambitious APEC outcome on climate change. Last week, he announced a significant new initiative aimed at bringing together the top 15 global emitters and energy users in a cooperative framework which mirrors closely the path-breaking work of the Asia-Pacific Partnership on Clean Development and Climate (AP6) which Australia helped launch at the start of last year.

On the eve of the G8 meeting in Germany, I hope leaders build on these constructive ideas in a way that supports meaningful global action.

Australia already has a highly-developed set of regional initiatives aimed at practical outcomes on climate change. We have helped to establish more than 100 AP6 projects working on low-emissions technologies and practices and joining forces in crucial areas such as clean coal technology and renewable energy.

Our strategic Clean Coal partnership with China is another vital instrument aimed at what matters in this debate. If we do not find good solutions which allow for the ongoing use of coal while avoiding the release of $\mathrm{CO} 2$ into the atmosphere, we do not have a solution to managing global emissions.

Stewardship of the world's forests is also critical to reducing greenhouse emissions. Rapid deforestation, including in APEC economies, contributes almost 20 per cent of global emissions.

Australia has pledged $\$ 200$ million as part of a Global Initiative on Forests and Climate. We are working with partners such as Indonesia and Papua New Guinea to reduce deforestation and to promote better forestry practices. 
Again, this is effective action, not words or symbolic gestures. If we were to halve the global rate of deforestation we could reduce greenhouse gas emissions by three billion tonnes a year -that is equivalent to more than five times Australia's total annual emissions and about 10 times the emissions reductions that will be achieved during the first commitment period of the Kyoto Protocol.

Last week I received the report of the Emissions Trading Task Force and on Sunday I announced that Australia will move to a comprehensive cap and trade system beginning no later than 2012.

Australia is the first country in the APEC region to commit to a full cap and trade system. Recognising the diversity of the APEC forum, a realistic scenario in coming years is one in which sub-sets of regional economies explore linking national systems and climate change strategies.

Our strategy in APEC is to work in a spirit of co-operation and in a way that respects national sovereignty and recognises regional diversity.

Again, the virtue of APEC is that it allows commitments to be made by countries in a model that fosters voluntary cooperation. Progress this year has already been made on transport and energy initiatives.

For example, technical and operational improvements to flight paths and ground handling can significantly reduce aviation emissions. Following agreement by APEC Transport Ministers, Australia will shortly host the first APEC High-level Seminar to bring together public and private sector experts to advance practical ways to reduce aviation emissions.

In addition, APEC Energy Ministers agreed in Darwin to strengthen cooperation on energy security and trade and to launch a new voluntary peer review mechanism to focus in the first instance on energy efficiency. 


\section{Conclusion}

Australia approaches this APEC year with determination and ambition, tempered by realism. Building consensus on difficult issues in such a diverse region is always challenging.

Australia has invested a lot in APEC since 1989. Now we must take the next steps to ensure it remains the preeminent forum in the Asia Pacific region. Australia and our APEC partners have an enormous stake in APEC rising to the challenges of global governance in the $21^{\text {st }}$ Century.

The script for an Asia Pacific Century is still to be written. As one who has never been enamoured of economic determinism, I understand fully the importance of ideas and leadership in shaping our shared future.

This year is Australia's opportunity to lead in APEC. We don't intend to waste it. 